\title{
Treatment of thumb-sucking habit using a fixed tongue crib appliance - a case report and literature review
}

SADJ June 2019, Vol. 74 No. 5 p239 - p242

D Reddy', SM Dawjee ${ }^{2}$

\section{SUMMARY}

A prolonged thumb sucking habit is associated with certain dental malocclusions. Numerous techniques and appliances have been reported for the treatment of thumb sucking, all having varying degrees of success.

This report presents a clinical case of a seven year old female patient with thumb sucking habit and an anterior open bite.

Through careful motivation, good patient compliance and a fixed tongue crib, the habit ceased and there was spontaneous correction of the anterior open bite within a treatment period of six months.

\section{Keywords}

Thumb-sucking, anterior open bite, fixed tongue crib.

\section{INTRODUCTION}

Oral health care providers are often consulted by concerned parents of children who have a thumb/fingersucking habit, wanting to know its cause and how it can be corrected.

This article presents a literature review of the causes of thumb sucking, as well as modalities that have been employed in the treatment of the habit, followed by a case presentation.

Sucking is a fundamental behaviour in the new-born infant. $^{1}$ It appears in two forms: nutritive, which provides nourishment, and non-nutritive, such as pacifier use and digit sucking, which provides comfort and a sense of security. ${ }^{2}$ Thumb-sucking is a common habit in children, and is regarded to be harmless up to the age of four to five years. ${ }^{3,4}$

Author affiliations:

1. Duren Reddy: $B C h D, P D D$, Private Practice.

2. Salahuddien M Dawjee: $B C h D, B C h D$ Hons, MSc (Odont), MDent (Ortho), PGDip IRE, PhD, Head, Department of Orthodontics, School of Dentistry, University of Pretoria, South Africa. ORCID Number: 0000-0001-9245-6563

Corresponding author: Salahuddien M Dawjee

Private bag X20, Hatfield, Pretoria, 0028.

Email: s.dawjee@up.ac.za

Author contributions:

1. Duren Reddy: $60 \%$

2. Salahuddien M Dawjee: $40 \%$

\section{AETIOLOGY}

There are three theories that attempt to explain the aetiology of prolonged non-nutritive sucking habits ${ }^{5}$ :

\section{Insufficient satisfaction of sucking needs during childhood (as a result of insufficient breastfeeding).}

Maternal nipple deprivation may be followed by apparent emotional confusion and frustration, leading to an inappropriate replacement of the nipple by a digit or pacifier. ${ }^{6}$

Breathing, swallowing, mastication and speech articulation are developed during breastfeeding and any imbalance in these systems might lead to unsatisfied sucking needs ${ }^{7}$.

\section{Learned behaviour}

The learned behaviour theory describes digit sucking as innate behaviour that becomes a habit, and, because thumb-sucking is soothing to the infant, the habit persists in some children when they are bored, tired or anxious. ${ }^{8}$

The innate nature of sucking is supported by ultrasound pictures of foetuses indulging in the habit in-utero. ${ }^{9}$ Further support of the learned behaviour theory may be seen in a study which found that the subjects with finger-sucking siblings were more likely to also demonstrate persistent finger-sucking. ${ }^{10}$

\section{Emotional theory}

The emotional theory is Freudian-based and relates finger-sucking to the oral phase of child development. Should the habit continue beyond the oral phase of child development, it becomes a fixation. Digit/finger sucking at a later stage is usually considered a sign of regression, and fixation and regression are the signs of emotional disturbance. ${ }^{7}$

Support for the emotional theory may be found in studies that found a greater incidence of thumb-sucking in children who, as infants, had been left to fall asleep alone, compared with infants who enjoyed the presence of a parent at the onset of sleep..$^{11,12}$

In support of these findings, the results of a recent study suggest that solitary sleeping in infants is a predictor of insecure attachment. ${ }^{13}$ 
If the habit continues beyond the age of four to five years it is associated with dental changes in the primary, mixed and secondary dentition, such as an anterior open bite, ${ }^{8}$ which frequently leads to a secondary tongue thrust habit. ${ }^{14}$ Other changes include: Class II molar and canine relationship, ${ }^{15}$ excessive overjet, ${ }^{16,17}$ maxillary protrusion, ${ }^{18}$ posterior cross bite, ${ }^{19}$ digital deformity ${ }^{20}$ and paronychia. ${ }^{21}$ The adverse effects associated with thumb sucking are dependent on its frequency, intensity, duration and position of the digit in the mouth. ${ }^{22,23}$

\section{MANAGEMENT}

Breastfeeding for six months or more has been reported to protect against the development of pacifier sucking habits. ${ }^{24}$ Breastfeeding and bottlefeeding also involve different orofacial muscles which possibly have different effects on the harmonic growth of the maxilla and dental arches. ${ }^{25,26}$

Various modalities have been reported for treating a thumb sucking habit. These include:

- Time-out, in which a reinforcer is removed whenever thumb-sucking occurs. For example, a mother could stop reading a story whenever thumb-sucking occurred.

- When the child removed his/her thumb from their mouth, the mother immediately resumed reading the story. ${ }^{27}$

- Positive reinforcement, such as verbally praising the absence of sucking or placing reward stickers on a calendar.

- Negative or aversion therapies, such as applying a foul-tasting oil on thumbs. A sock, adhesive strip, splint, or glove can be used to remind the child not to put the thumb or fingers in the mouth.

- Competing response therapy, such as squeezing an object whenever the child feels the impulse to thumb or finger-suck.

- Dental appliances.9.,28

- Hypnosis. ${ }^{29}$

- An awareness enhancement device (AED), which produces a tone each time an individual raises a hand to the head.

Thumb-sucking occurs most frequently when the child is alone. ${ }^{30}$ Therefore, a modality that does not require close monitoring of the child may be more successful in treating the habit.

A dental appliance is one such modality. Numerous dental appliances have historically been used to treat the thumb-sucking habit. Examples include: the sharp rake, the blunt rake, lingual spurs, the vertical crib, the palatal bar, the horizontal crib, the Graber appliance and the blue grass appliance. While some of these appliances have been described as cruel and inhumane, ${ }^{30}$ the palatal crib (vertical crib/tongue crib) has been reported to be successful in treating a thumb sucking habit. ${ }^{32-35}$

The habit may intensify if the child is criticised, nagged or threatened. The parent should therefore be patient and empathetic. Discretion should be used by both the clinician and the parent as to when/whether treatment for thumb-sucking should be pursued. Caution should be exercised in cases when, for example, a child older than four experiences the loss of a family member or pet, or is subject to fear or pain, thumb sucking may then become a temporary coping strategy ${ }^{36}$.

\section{CLINICAL REPORT}

A seven year old female patient in the mixed dentition presented with an open bite (Fig. 1). She displayed a convex profile and an acute naso-labial angle. She had an Angle Class I Type 2 malocclusion, $6 \mathrm{~mm}$ overjet and a $3 \mathrm{~mm}$ anterior open bite.

Evaluation of oral function showed a tongue thrust when swallowing and an intermittent thumb sucking habit. Skeletal classification was Class I (Wits) and Class I| (Steiner). Canines were developing normally, the sequence of eruption was normal and both upper and lower incisors were proclined and protruded.
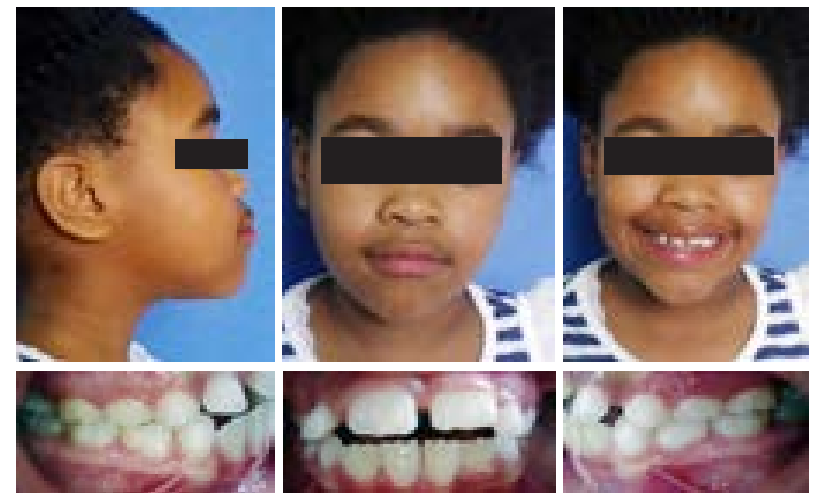

Figure 1. Pre-operative extra-oral and intra-oral photographs.

Good compliance and motivation is essential for interceptive orthodontic treatment. To achieve this, the patient was shown photographs of children her age with normal occlusion and then shown pictures of her occlusion.

She was informed that these complications could extend into the secondary dentition and was shown pictures of adults with an anterior open bite and/or excessive overjet. She was informed that if she stopped the thumb-sucking, those malocclusions could possibly be avoided. She was informed that the appliance was placed as a reminder and not as a punishment.

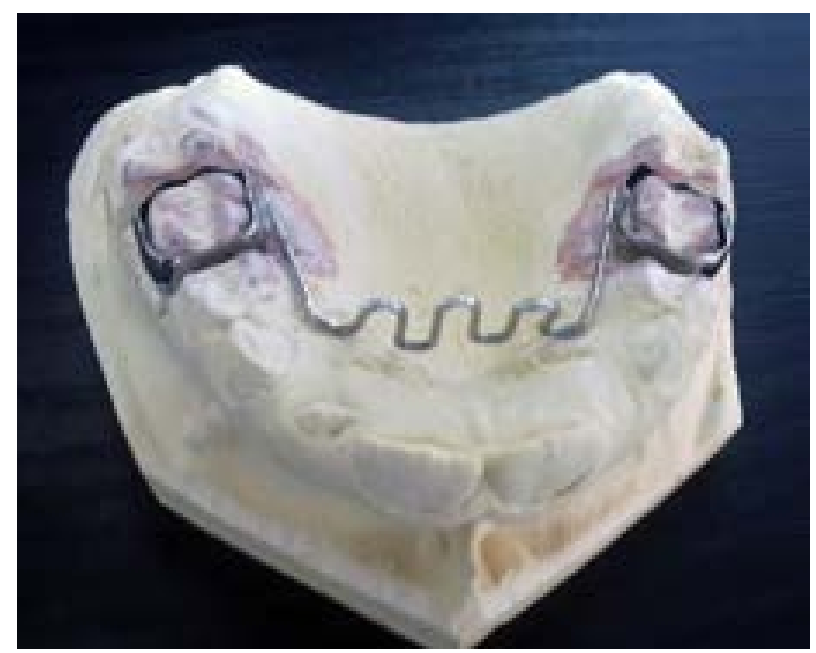

Figure 2. Appliance design 
A tongue crib was constructed of $0.7 \mathrm{~mm}$ stainless steel wire and welded to bands on the second primary molars. The thumb-sucking habit ceased after four weeks. The patient's anterior open bite had spontaneously corrected after four months. The appliance was removed after six months.

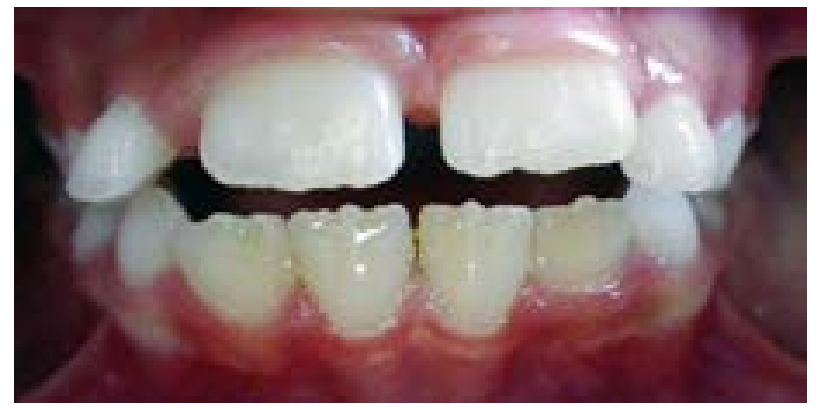

Figure 3. Pre-operative intra-oral photograph .

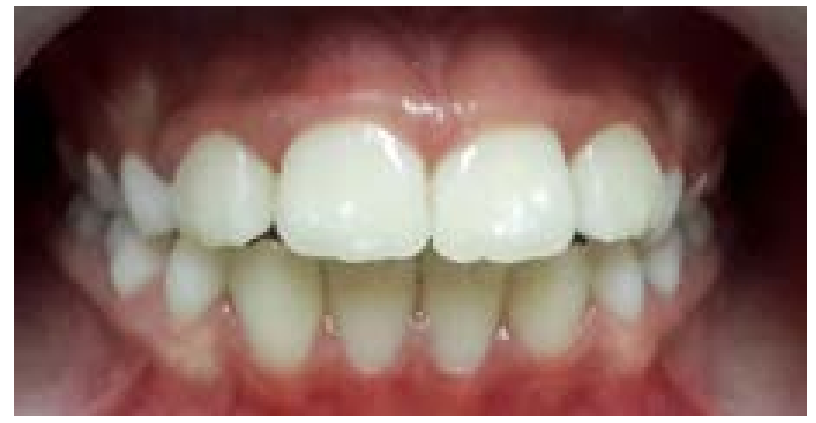

Figure 4. Post-operative intra-oral photograph.

\section{DISCUSSION}

Prolonged thumb sucking is often associated with an anterior open bite, which frequently leads to a secondary tongue thrust habit. An appropriate appliance will therefore address both of these habits. ${ }^{25}$

Since the palatal crib ameliorates an anterior open bite by preventing the tongue from resting on the teeth, it should also extend far enough inferiorly to keep the tongue from positioning itself below the crib. To achieve this, the crib should extend to the lingual gingival margin of the lower incisors and should extend transversely from the upper left canine to the upper right canine ${ }^{37}$.

\section{CONCLUSION}

Through careful motivation, good patient compliance and a fixed tongue crib, a thumb-sucking habit can be successfully treated with spontaneous correction of the anterior open bite.

\section{References}

1. Raven JJ. Sucking habits and occlusion in 3-year-old children. Scand J Dent Res. 1976; 84:204-9.

2. O'Brien TH, Lachapelle D, Gagnon PF, Larocque I, MaheuRobert LF. Nutritive and non-nutritive sucking habits: a review. J Dent Child. 1996; 63:321-7.

3. Peterson JE. Schneider PE. Oral habits. Pediatr Clin North Am. 1991; 38:1289-96.
4. Maguire JA. The evaluation and treatment of pediatric oral habits. Dental Clinics of North America 2000; 44(3):659-69.

5. Hanna LM, de Araújo RJ, Paganini AL. Analysis of the relation of intrauterine digital sucking with the permanence of the habit in the post birth child. Journal of Research in Dentistry 2016; 3(4):741-51.

6. Mobbs EJ, Mobbs GA, Mobbs AED. Imprinting, latchment and displacement: a mini review of early instinctual behaviour in newborn infants influencing breastfeeding success. Acta Paediatr. 2016; 105:24-30.

7. Bishara SE, Larsson E. Finger habits: their effects and their treatments--Part 1. Dental Assistant 2007; 76(1):14-6.

8. Davidson L. Thumb and finger sucking. Pediatrics in Review 2008; 29(6): 207-8.

9. Levine RS. Briefing paper: Oral aspects of dummy and digit sucking. British Dental Journal 1999; 186(3):108.

10. Da Costa OO, Orenuga OO. The digit sucking habit and related factors: Observations from a child dental health clinic in Nigeria. Afr J Med Med Sci. 2003; 32:167-71.

11. Ozturk M, Ozturk OM. Thumbsucking and falling asleep. $\mathrm{Br} \mathrm{J}$ Med Psychol. 1977; 50:95-103.

12. Wolf A, Lozoff B. Object attachment, thumbsucking, and the passage to sleep. J Am Acad Child Adolesc Psychiatry. 1989; 28:287-92.

13. Mileva-Seitz VR, Luijk MPCM, van Ljzendoorn MH, Bakermans-Kranenburg MJ, Jaddoe VWV, Hofman A, Verhulst FC, Tiemeier H. Association between infant night-time sleep location and attachment security: no easy verdict. Infant Ment Health J. 2016; 37:5-16.

14. Van Norman RA. Digit-sucking: a review of the literature, clinical observations and treatment recommendations. Int J Oral Myol. 1997; 23:14-34.

15. Farsi NMA, Salama FS. Sucking habits in Saudi children: prevalence, contributing factors and effects on the primary dentition. Pediatr Dent. 1997; 19:28-33.

16. Warren JJ, Bishara SE, Steinbock KL, Yonezu T, Nowak AJ. Effects of oral habits' duration on dental characteristics in the primary dentition. J Am Dent Assoc. 2001; 132(12):1685-93.

17. Adair SM, Milano M, Lorenzo I, Russel C. Effects of current and former pacifier use on the dentition of 24 to 59 month old children. Pediatr Dent. 1995; 17:437-44.

18. Fukata O, Braham RL, Yokoi K, Kurosu K. Damage to the primary dentition from thumb and finger (digit) sucking. ASDC J Dent Child. 1996; 63:403-7.

19. Warren JJ, Bishara SE. Duration of nutritive and non-nutritive sucking behaviors and their effects on the dental arches in the primary dentition. Am J Orthod Dentofacial Orthop. 2002; 21:347-56.

20. Srinivasan J, Hutchinson JW, Burke FD. Finger sucking digital deformities. J Hand Surg Br. 2001; 26:584-8.

21. Durdu M, Ruocco V. Clinical and cytologic features of antibiotic-resistant acute paronychia. J Am Acad Dermatol. 2014; 70:120-6.

22. Lindner A, Modeer T. Relation between sucking habits and dental characteristics in preschool children with unilateral crossbite. Scand J Dent Res. 1988; 97:278-83.

23. Van Norman R. Why we cannot afford to ignore prolonged digit sucking. Contemporary Pediatrics 2001; 2:61-80.

24. de Holanda AL, dos Santos SA, de Sena MF, Ferreira MA. Relationship between breast and bottle-feeding and non-nutritive sucking habits. Oral Health Prev Dent. 2009; 7(4):331-7.

25. Viggiano D, Fasano D, Monaco G, Strohmenger L. Breast feeding, bottle feeding, and non-nutritive sucking; effects on occlusion in deciduous dentition. Arch Dis Child. 2004; 89(12):1121-3.

26. Barbara E, Thomaz AF. Maternal breastfeeding, parafunctional oral habits and malocclusion in adolescents: A multivariate analysis. Int J Pediatr Otorhinolaryngol. 2012; 76:500-6.

27. Knight MF, McKenzie HS. Elimination of bedtime thumbsucking in home settings through contingent reading. J Appl Behav Anal. 1974; 7(1):33-8. 
28. Houten R, Rolider A. The use of response prevention to eliminate nocturnal thumbsucking. J Appl Behav Anal. 1984; $17: 509-20$.

29. Grayson D. Hypnotic intervention in a 7-year-old thumbsucker: A case study. Am J Clin Hypn. 2012; 54(3):195-201.

30. Stricker JM, Miltenberger RG, Garlinghouse MA, Deaver CM, Anderson CA. Evaluation of an awareness enhancement device for the treatment of thumb sucking in children. J Appl Behav Anal. 2001; 34(1):77-80.

31. Moore NL. Suffer the little children: fixed intraoral habit appliances for treating childhood thumbsucking habits: a critical review of the literature. Int J Oral Myol. 2008; 34:46-78.

32. Berger J, Janisse F. Treatment options for anterior open bite. Ontario Dentist 2013; 90(5):30-5.

33. Asiry MA. Anterior open bite treated with Myofunctional Therapy and palatal crib. J Contemp Dent Pract. 2015; 16(3): 243-7.

34. Sayin M, Akin E, Karacay S, Bulakbasi N. Initial effects of the tongue crib on tongue movements during deglutition: a cine-magnetic resonance imaging study. Angle Orthodontist 2006; 76(3): 400-5.

35. Villa NL. Changes in the dentition secondary to palatal crib therapy in digit-suckers: a preliminary study, Pediatric Dentistry 1997; 19(5):323-6.

36. Friman PC, Liebowitz JM. An effective and acceptable treatment alternative for chronic thumb-and finger-sucking. J Pediatr Psychol. 1990; 15:57-65.

37. Feu D, Menezes LM, Quintão AP, Quintão CC. A customized method for palatal crib fabrication. J Clin Orthod. 2013; 47(7):406-12.

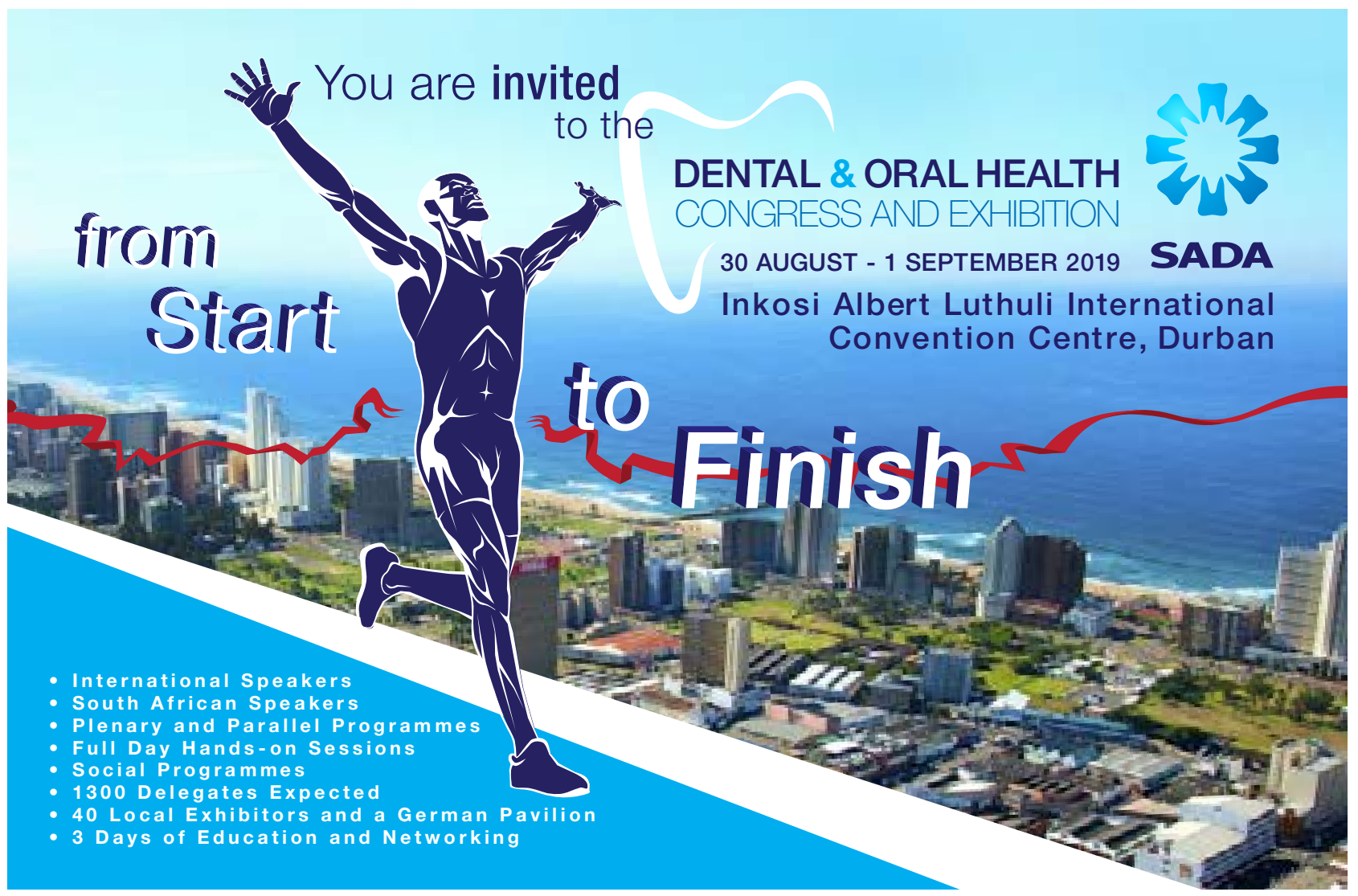

